\title{
A AÇÃO MISSIONÁRIA DA ARQUIDIOCESE DE NATAL, RÍO GRANDE DEL NORTE (BRASIL)
}

\author{
M. M. PAIVA \\ Universidade Rio Grande do Norte \\ mmarlupaiva3@gmail.com
}

Artigo submetido em junho/2016 e aceito em julho/2016

DOI: $10.15628 /$ holos.2016.4684

\section{RESUMO}

Após a Segunda Grande Guerra a cidade do Natal, capital do Estado do Rio Grande do Norte, enfrenta sérios problemas de ordem social e econômica. Nesse contexto, a Arquidiocese de Natal iniciou novas práticas pastorais que extrapolaram o culto puramente individual, voltando-se para práticas sociais, particularmente com a criação do Serviço de Assistência Rural-SAR, em 1949. A Arquidiocese direcionou sua ação educativa para o meio rural, no campo da educação não-formal, cujos desdobramentos redundaram em um apostolado diferente do até então praticado. Foram criadas missões rurais, cooperativas de produção artesanal, sindicatos rurais, escolas de alfabetização pelo rádio, formas inovadoras de organização das comunidades. $O$ ingresso no campo da alfabetização de jovens e adultos, em 1958, com a criação das Escolas Radiofônicas, levando a educação de base para as regiões rurais do Estado, proporcionou a conformação de um novo campo de difusão do ideário católico. O sucesso dessa experiência de alfabetização, provocou a criação do Movimento de Educação de Bases-MEB, mediante convênio entre o MEC e a CNBB, em 1961, ampliando a experiência para as regiões subdesenvolvidas do Norte, Nordeste e CentroOeste. O MEB atuou numa linha desenvolvimentista, pregando o crescimento da economia nacional como saída para a crise econômica brasileira. Dada essa conotação, a Igreja preservou, a hegemonia na comunidade de fiéis da área rural, neutralizando a influência comunista, mediante uma proposta de evangelização, onde estava implícita a elevação do nível de vida das populações rurais, embora em harmonia com a ordem capitalista vigente.

PALAVRAS-CHAVE: Ação missionária, Igreja Católica. Educação, Natal.

\section{THE MISSIONARY WORKS OF NATAL'S ARCHDIOCESE, RIO GRANDE DO NORTE (BRAZIL)}

\section{ABSTRACT}

After the II World War in Natal's city, Rio Grande do Norte's capital, faces serious problems of social and economical order. In this context, Natal's Archdiocese began new pastoral practices that went beyond the purely individual worship, turning to social practices, particularly with the creation of the Rural-SAR Assistance Service in 1949. Therefore, the Archdiocese directed its educational activities to the rural areas, in the field of non-formal education, in which developments resulted in an apostolate different of till then practiced. It were created rural missions, craft productions cooperatives, the rural trade union, literacy school by the radio, innovative forms of community organization. The entry in the field of young and adult literacy, in 1958, provided the conformation of a new field of diffusion of the Catholic ideology with the creation of the Radio Schools, bringing the basic education to rural regions of the State. The success of the literacy experience caused the creation of the Basic Education Movement - MEB, under an agreement between MEC and the CNBB in 1961, expanding the experience to undeveloped areas of North, Northeast and Midwest. The MEB acted in a developmental line, preaching the growth of national economy as a way out of the brazilian crisis. Due to this pedagogical connotation to its actions the Church preserved the hegemony in the faithful community of rural area, neutralizing the communist influence, through an evangelization proposal, which was implied the raising of the living level of rural populations, although in harmony with the current capitalist order.

KEYWORDS: Missionary works, Catholic Church, Natal, Educacion. 


\section{APRESENTAÇÃO}

Os anos que se seguiram à Segunda Grande Guerra revelam a cidade do Natal, capital do Estado do Rio Grande do Norte, Nordeste do Brasil, enfrentando sérios problemas de ordem social e econômica. A cidade encontrava-se devastada pelas conseqüências do fenômeno cíclico da seca e pela retirada das tropas americanas que haviam instalado uma base militar no vizinho município de Parnamirim. Esta base servira de passagem para as tropas que se dirigiam ao front da guerra, particularmente para o continente africano. Para uma maior dimensão do significado desse acontecimento, lembremos que a cidade do Natal possuía cem mil habitantes em 1950 e a Base de Parnamirim, ou Parnamirim Field como era nomeada, teve ocasião de alojar dez mil soldados, portanto, $10 \%$ de sua população. Por outro lado, atraído pelo que a cidade parecia oferecer, um excessivo contingente de pessoas vindas de municípios e Estados vizinhos ali se instalou.

O término da Grande Guerra deixou essa população sem o ganho, aparentemente fácil, que provinha de práticas pouco recomendáveis socialmente, a exemplo do jogo de azar e da prostituição, embora também fosse encontrado grande número de desempregados entre empregadas domésticas, trabalhadores no comércio, nos bares, entre outros. É nesse contexto que a Arquidiocese de Natal, dizendo-se preocupada com essa problemática social que grassava na cidade e também pelo êxodo rural, como se falava à época, inicia um processo de conformação e difusão de novas práticas pastorais disseminadas em determinados setores religiosos e leigos.

Entretanto, não podemos deixar de lembrar, que os anos pós-Segunda Guerra também delinearam a guerra fria, num contexto marcado pelo reordenamento do capital e delimitação de duas áreas de poder: os denominados bloco ocidental cristão, liderado pelos Estados Unidos (EUA), e o bloco oriental socialista, liderado pela União das Repúblicas Socialistas Soviéticas (URSS). A Igreja Católica, embora mais alinhada ao bloco ocidental cristão, não ignorava os desdobramentos nefastos dessa política dual. Encontramos, em documentos pesquisados nos Arquivos da Arquidiocese de Natal, referências ao comunismo ateu e ao capitalismo selvagem, demonstrando a Igreja sua insatisfação com a divisão que provocava nos diversos países. Como desdobramento desse posicionamento, observamos o aparecimento de práticas mais modernas nas atividades desenvolvidas pela Igreja, estimulando, poucos anos depois, a conformação de um campo político alternativo ao proposto pelas duas potências dominantes, a denominada terceira via.

Essas ações da Igreja extrapolaram o culto puramente individual e deslocaram-se para o espaço da sociedade. Neste estudo, analisamos algumas dessas práticas, em função da conformação de um novo campo doutrinário-evangelizador, pois, como diz Certeau, no livro $\mathrm{A}$ escrita da história: "Tornando-se um elemento social de diferenciação religiosa, a prática ganha uma pertinência religiosa nova." (1982, p. 36). Assim, as práticas religiosas da Arquidiocese de Natal e as modificações expressas no seu apostolado, se apresentam, no discurso da Igreja, como "um apostolado de ação. Exorbitando do âmbito das Igrejas e das sacristias" (IGREJA CATÓLICA, 1950).

No final da década de 1940, precisamente em 22 de dezembro de 1949, na perspectiva desse espírito renovador, a Arquidiocese de Natal criou o Serviço de Assistência Rural (SAR), organismo que direcionou suas práticas educativas para o meio rural. Esse organismo desenvolveu atividades variadas no campo da educação não-formal, cujos desdobramentos redundaram em um 
apostolado diferente do que até então era praticado: foram criadas missões rurais, cooperativas de produção artesanal, sindicatos rurais, clubes agrícolas, escolas de alfabetização pelo rádio, entre outras.

Podemos observar em relatórios de trabalho emitidos pelo SAR a preocupação primeira com a organização social da comunidade. Em um desses relatórios, denominado Sucinto Relato das atividades desenvolvidas pelo Serviço de Assistência Rural, no ano de 1956, encontramos na Introdução: O Serviço de Assistência Rural estabeleceu em 1956, a sua linha de trabalho, concentrando seus esforços em atividades específicas de organização social da comunidade. (p. 1)

Mas, o que significava na prática essa "organização social da comunidade"? No desenrolar do Relatório vemos no item II - ATIVIDADES DESENVOLVIDAS, o elenco das seguintes atividades:

1. Formação de pessoal voluntário e técnico - que consistia na execução de cursos de treinamento para formação de lideranças, cursos para professoras de caça e pesca, cursos para líderes cooperativistas, curso de atualização de conhecimentos, curso de economia doméstica, curso de líderes paroquiais.

2. Missão Rural do Agreste - para essa atividade, o Relatório rezava: “O trabalho de equipe, de caráter educacional visou levar os locais a descobrirem os recursos e deficiências de sua comunidade, movendo-os a coordenar iniciativas no sentido de promoverem o engrandecimento da terra mãe." (p. 1-2)

Essas atividades relacionadas apontam para formas inovadoras de organização das comunidades. A Igreja opta por novo campo de atuação. Além do tradicional ensino nas escolas e do também tradicional culto praticado nas igrejas. Safira Bezerra Ammann (1991), em seu livro Ideologia do Desenvolvimento de Comunidade no Brasil, descreve essa técnica de trabalho que, de acordo com definição da ONU, era entendida como um

[...] processo através do qual os esforços do próprio povo se unem aos das autoridades governamentais, com o fim de melhorar as condições econômicas, sociais e culturais das comunidades, integrar essas comunidades na vida nacional e capacitá-las a contribuir plenamente para o progresso do país. (1991, p. 32).'

A autora, respaldando-se em publicações da ONU, diz que dois ingredientes básicos do Desenvolvimento de Comunidade são: participação ativa do povo nas ações para melhorar seu nível de vida e apoio técnico governamental. Pelas pesquisas que realizamos, identificamos que apenas parte desses denominados ingredientes básicos podem ser observados nas práticas desenvolvidas pela Igreja, pois avaliamos que, em alguns momentos, talvez até tenham impedido um desenvolvimento maior das populações rurais, uma vez que retirava a sua autonomia e capacidade de decisão. Era um desenvolvimento tutelado. Em relatórios do SAR pesquisados, é evidente a importância adquirida por essa técnica na organização das comunidades rurais e a parceria que foi firmada com entidades governamentais. O relatório das atividades desenvolvidas pelo Serviço de Assistência Rural (SAR). no Rio Grande do Norte, de 1954, diz:

No Estado do Rio Grande do Norte, o Ministério de Agricultura e o Ministério de Educação e Cultura, têm atuado regulamentando atividades, orientando e estimulando a iniciativa particular. O Serviço de Assistência Rural, - instituição pertencente à Ação Católica, cujo objetivo é a organização das comunidades 
rurais, através do processo de educação de base, tem recebido o mais pronto e integral apoio do Ministério de Agricultura e de Educação e Cultura. (1958, p. 2).

Dessa forma, a Igreja Católica, no Rio Grande do Norte, desenvolveu seu apostolado de uma forma diferente da habitual. A intervenção da Ação Católicaii deu uma nova feição aos trabalhos desenvolvidos, apresentando uma aproximação maior das práticas modernizadoras, mais voltadas para o social. Poderíamos afirmar que essas práticas antecederam aos ditames proclamados pelo Concílio Vaticano II, pois, em publicação de documentos daquele Concílio encontramos a citação: "a doutrina católica não deve ser somente verdade a ser explorada pela razão sob a luz da fé, mas sim palavra geradora de vida e de ação." (VIER, p. 9).

De todas as ações então desencadeadas, a alfabetização pelo rádio - as escolas radiofônicas - e o sindicalismo rural foram as que alcançaram maior dimensão, estenderam-se por todo o Estado do Rio Grande do Norte. No que se refere à alfabetização pelo rádio, com a adesão das Dioceses de Mossoró e Caicó, à época, respectivamente, segunda e terceira maiores cidades do Estado, a Igreja conseguiu uma inserção no meio rural que cobria quase a totalidade física do Estado, sem falar no poder de alcance das ondas sonoras do rádio, que extrapolava esse espaço geográfico. Com o sindicalismo rural a Igreja conseguiu penetrar no meio dos trabalhadores rurais, disseminar o ideário católico, desenvolvendo uma ação que poderíamos chamar de missionária.

À época, o atraso nas relações de trabalho no meio rural da região nordeste dificultava a introdução dessas práticas consideradas comunistas pelas camadas dirigentes da sociedade, mesmo sendo lideradas pela Igreja, No entanto, é importante ressaltar, essas práticas não ocorreram na Igreja enquanto instituição, mas em parcela do clero e, particularmente, pela atuação da Ação Católica, ou seja, pela atuação conjunta da Igreja com o movimento laico.

Esse processo de renovação das práticas pastorais, introduzindo atividades antes pouco utilizadas, notadamente a inserção e valorização do leigo no movimento pastoral, o uso de tecnologias modernas - como o rádio, apontam na direção da conformação de estratégias de expansão que demarcam um novo espaço sócio-cultural, com significados sociais próprios. 0 sistema rádio-educativo foi o mais importante dos recursos utilizados. Cava, \& Montero (1991:224, apud Gê, 1991:59) dizem que "a grande maioria das emissoras católicas foi criada ao longo dos dez anos que vão de 1954 à 1964". Dada a sua importância, o papa Pio XII, em 1957, editou a encíclica Miranda Prorsus, que aborda a questão dos meios de difusão e sua utilização no ensino católico e na educação das massas.

Nessas práticas renovadoras, a instituição católica, em busca de uma solução cristã para os problemas sociais, disseminava um discurso de entendimento entre as classes, evitando provocar desequilíbrios ou crises, em prol da harmonia na sociedade. Havia no Brasil, um discurso de preocupação com a questão agrária. Nessas práticas renovadoras, modernas, a utilização do rádio poderia representar uma possibilidade de maior alcance. À época, os meios de transporte eram extremamente precários e a pobreza e concentração de renda na região nordeste exigiam medidas urgentes. O rádio poderia multiplicar o discurso católico, expandindo a voz da Igreja no meio rural alcançando parcela mais significativa da população.

O ingresso no campo da alfabetização de jovens e adultos, em 1958, com a criação das Escolas Radiofônicas, levando a educação de base para as regiões rurais do Estado, proporcionou a conformação de um novo campo de difusão do ideário católico. O conceito de educação de base, então difundido pela UNESCO, previa a aquisição de um mínimo de conhecimentos (leitura, escrita, 
cálculos, entre outros) necessários à inserção e domínio do indivíduo em seu meio social; nas práticas da Igreja esse conceito evoluiu, com a criação do Movimento de Educação de Base (MEB), para o de "formação integral do homem, para sua promoção" (MEB, 1974, Relatório Anual de 1962. In: Fávero: 1984).

No II Encontro dos Bispos do Nordeste, em 1959, sediado em Natal (RN), os prelados presentes publicaram a II Declaração dos Bispos do Nordeste, divulgando os entendimentos mantidos com o Governo e as providências tomadas para o propalado desenvolvimento da região. Naquela Declaração, os bispos expressaram um discurso onde a necessidade do planejamento econômico para o Nordeste era afirmada, embora não descuidassem de ressaltar os cuidados com os aspectos humanos e sociais, pois o desenvolvimento econômico

[...] só atingirá sua eficiência plena se se apoiar no esforço consciente e voluntário das forças atuantes de toda a comunidade, para o que se torna urgente a preparação, em todos os seus níveis, de líderes, especializados em modernas técnicas de organização comunitária, tais como a promoção do cooperativismo, do serviço de extensão rural e de outros processos de educação de base (ENCONTRO dos Bispos do Nordeste 2, 1959, p. 18).

Embora a Arquidiocese de Natal tenha desenvolvido outras atividades educativas, como a criação dos sindicatos rurais, publicação do jornal A Ordem, ou a fundação de cooperativas de produção artesanal, nesta pesquisa priorizamos a criação das Escolas Radiofônicas, por ser uma experiência educacional inovadora, que alcançou um campo maior de atuação no Estado, atingindo espaços antes inacessíveis, demonstrando estar a Igreja vigilante e apta a utilizar as novas tecnologias na sua atuação pastoral.

\section{ESCOLAS REDIOFÔNICAS}

Tendo iniciado suas práticas sócio-culturais, principalmente na periferia urbana da capital do Estado, a Arquidiocese de Natal estendeu essa estratégia de ação ao meio rural, com a criação, em 1949, do Serviço de Assistência Rural (SAR). No final da década de 1950, ingressou nas lides da alfabetização, com a criação das Es`colas Radiofônicas. Embora já na década de 1940 a Diocese de Natal faça referência, mesmo esporádica, à criação de uma rádio-escola, sua configuração ocorreu a partir do conhecimento da experiência de Mons. José Joaquim Salcedo, em Sutatenza (Colômbia).

No ano de 1957, D. Eugênio Sales, iii Bispo-auxiliar e um dos principais responsáveis pelas práticas sócio-culturais desenvolvidas pela Arquidiocese de Natal, foi designado, pela CNBB, em colaboração com o Escritório Técnico de Agricultura (ETA), organismo do ponto IV ${ }^{\text {iv }}$, para conhecer a experiência educacional desenvolvida pela Igreja colombiana.

No ano seguinte (1958), a Arquidiocese de Natal recebeu do Governo, pelo Decreto no 43.729, de 21 de maio de 1958, a concessão de um canal para instalação de uma rádio, que foi denominada Emissora de Educação Rural, inaugurada no dia 10 de agosto do mesmo ano. A primeira aula radiofônica foi levada ao ar no mês seguinte, atingindo os municípios de São Paulo do Potengi, São José do Mipibu, São Gonçalo do Amarante, Touros, Macaíba e Ceará-Mirim, todos localizados próximos à capital do Estado. 


\section{A ORGANIZAÇÃO DAS ESCOLAS RADIOFÔNICAS}

As Escolas Radiofônicas (ERs), quando surgiram, constituíram-se em mais um setor do SAR destinado à educação rural, assim se expressou uma ex-professora-locutora das Escolas Radiofônicas: "Quando as escolas começaram já existia o SAR com toda uma programação de clubes, centros sociais; as escolas entraram complementando a ação" (Maria Duarte de Araújo, entrevista). Desenvolveu, no início, um programa de educação de base em apenas 10 municípios do Rio Grande do Norte, área que integrava à Diocese de Natal. Em 1959, a Emissora de Educação Rural já atingia 36 municípios: 34 na Arquidiocese de Natal, 1 na Diocese de Caicó e 1 na de Mossoró. Foi, sem dúvida, um grande desenvolvimento alcançado pelas Escolas Radiofônicas.

O discurso expresso no Relatório do SAR/1959 considerava a experiência de educação de base pelo rádio "como vitoriosa", pois "a cultura antiga do nosso interior já apresenta traços de mudança, graças aos trabalhos da Emissora". Essa afirmação expressa uma estratégica valorização e difusão do trabalho político-pedagógico desenvolvido pela Arquidiocese, pois, apesar do SAR contar "com cerca de 800 líderes treinados o que permite uma recepção dirigida em quase todos os programas da Emissora, dedicados à zona rural" (Igreja Católica, SAR, 1959), o tempo é relativamente pequeno, para ocorrer qualquer mudança cultural mais consequente e/ou duradoura.

Documentos posteriores do Movimento de Educação de Base-MEB reconhecem que, após o primeiro ano de trabalho, portanto em 1962, embora as escolas, de uma maneira geral, apresentassem bons resultados, no que se refere à alfabetização, ainda enfrentavam, problemas de freqüência instável, evasão escolar e escola desligada da vida da comunidade. (MEB, 1982:29). Esse mesmo Relatório fazendo ouvir a voz da Igreja, anuncia que "todo o programa de atividades do Serviço de Assistência Rural visa a educação de base e portanto o acesso e fixação do homem ao solo".

Ferrari (1968:85), que estudou essa experiência, afirma que:

A educação de base - objeto do ensino radiofônico - visava não somente a alfabetização, mas também a conscientização e politização das populações rurais, [pois] o próprio método de alfabetização era um processo de conscientização e politização partindo não das tradicionais cartilhas de alfabetização, mas de termos como povo, voto, liberdade, libertação, trabalho, salário, direito, dignidade, justiça, doença, fome, união, força, sindicato, alfabetização, analfabeto, cristão, amor, responsabilidade etc.

No entanto, o método de alfabetização utilizado nesses primeiros anos, segundo depoimento de ex-professoras-locutoras entrevistadas, era o denominado método globalizante, que "aprenderam quando cursavam a Escola Normal", não existindo ainda a intencionalidade de politizar nessa linha de conscientização, o que veio a ocorrer a partir do MEB e da influência da Juventude Universitária Católica (JUC) e da Ação Popular (AP) na Equipe Nacional, que traçava as diretrizes político-pedagógicas dessa experiência educacional, o que veremos mais adiante.

Dentro da orientação do método globalizante, eram escolhidas unidades temáticas que correspondiam às programações desenvolvidas pelo SAR em determinado período, cujo conteúdo seria trabalhado durante as aulas, num espaço de aproximadamente um mês. Os demais 
conteúdos ou matérias deveriam girar em torno desse tema maior. As professoras-locutoras criavam tudo, não existindo nenhuma orientação externa.

Para desenvolver a programação, as Escolas Radiofônicas estavam estruturadas em três pilares: professora-locutora, responsável pela elaboração e transmissão das aulas na Emissora Rural; monitor, pessoa das comunidades trabalhadas, geralmente indicadas pelo pároco local, por possuir algum atributo de liderança na comunidade, ou mesmo por ser reconhecidamente uma boa pessoa e ter alguns rudimentos de leitura e cálculo. O monitor era, também, responsável pela matrícula dos alunos - "listava os alunos num papel e enviava para o SAR" (depoimento); rádio de frequência cativa, fornecido pelo SAR, além de ou-tros materiais, como lampião a querosene (quando não tinha energia elétrica, o que geralmente ocorria), giz, quadro de giz. Essa estruturação foi alterada com a criação do MEB em 1961.

O MEB, podemos afirmar, teve como inspiração primeira o II Encontro dos Bispos do Nordeste (1959), realizado em Natal (RN). Na "Declaração dos Bispos do Nordeste", os arcebispos e bispos presentes sugerem ao então Presidente Kubitscheck realizações a serem executadas na área da "Educação de Base e Promoção Operária".

Esse foi o primeiro passo para ampliação da experiência das Escolas Radiofônicas da Arquidiocese de Natal.

Nesse mesmo Encontro, D. José Távora, Arcebispo de Aracaju, em nome da CNBB, iniciou entendimentos com o Presidente eleito (porém ainda não empossado) Jânio Quadros (janeiro/1961 a agosto/1961) para ampliação dessas Escolas.

Como resultado desse entendimento, em contrapartida,

A CNBB se propôs a estruturar os esforços existentes através de um Movimento que coordenasse a ação comum. As atividades das Escolas Radiofônicas das Dioceses, juntamente com o setor de Educação de Base da RENEC, passariam a construir um novo organismo: o Movimento de Educação de Base (MEB)" (SPEYER, 1976, p. 6).

Em seguida surgiu o MEB, através do Decreto no 50.370, de 21 de março de 1961, assi-nado pelo Presidente Quadros, o qual previa que o Ministério da Educação e Cultura, em convênio com a CNBB, financiaria durante cinco anos o projeto de educação de base da CNBB, através da instalação de 15.000 Escolas Radiofônicas nas regiões subdesenvolvidas do Norte, Nordeste e Centro-Oeste.

A face expansionista da ação pedagógica da Igreja, que é também uma ação evangelizadora, estava se configurando claramente nessa teia de acontecimentos, que vinha sendo pouco à pouco elaborada. Como muito bem demonstrou Moscovici (1990), a religião possui a faculdade primordial de exercer pressão social, que se delineia como exterior a esse mundo terreno, possuindo um fundo psicológico, moral, se impondo pela coação dos laços sociais, consolidados por uma instituição (a Igreja), que se diz independente de fatores políticos ou econômicos. Ela está acima desse mundo terreno, simbolicamente, seus interesses estão circunscritos à outra dimensão, tendo possibilidades maior de integralizá-los. Podemos observar no episódio do MEB, a relativa facilidade da Igreja conseguir realizar convênio com o Governo federal, numa época em que as iniciativas na área da educação popular (considerando-se o MEB como educação popular) 
eram estratégias de governos nomeados de esquerda, o que não era o caso do Governo federal brasileiro naquele momento histórico.

A partir da criação do MEB, as Escolas Radiofônicas ganharam novo direcionamento. Esse Sistema surgiu como um movimento da Igreja e se auto-denomina,

[...] Não um movimento de apostolado, enquanto apostolados dos cristãos que nele engajaram, mas enquanto [...] um movimento de Igreja. É um movimento de instituição da CNBB. Não é só hierarquia, nem é um movimento apostolado dos leigos. É um movimento da Igreja. (MEB, 1982).

Essa definição do MEB como Igreja põe em destaque que é a própria instituição eclesial a responsável direta por suas atividades. Evidencia uma intencionalidade em organizar seus quadros - os leigos - configurando um novo campo católico e uma novo ideário.

Apesar das circunstâncias, desde 1962 aconteciam mudanças nas atividades das Escolas Radiofônicas. Observe-se o que diz Maria Araújo D. de Carvalho, ex-professora-locutora, (informação verbal):

No início, a Escola Radiofônica era um complemento da ação do SAR, mas, depois, em 62, a Escola Radiofônica já passou a ter uma ou-tra conotação, ser entendida de uma outra forma. Então MEB passou a ser não só Escola Radiofônica... a Escola Radiofônica era apenas o centro de organização de todos os trabalhos, então era, por exemplo, a Escola que motivava a criação do sindicato, era a Escola que motivava a criação de cooperativa, era a Escola que organizava grupos de jovens, grupos de mães... então a Escola passou a ser o centro da comunidade e todas as atividades que antes eram desenvolvidas pelo SAR, passaram a ser entendidas pelos monitores, alunos e comunidade, como sendo MEB, tudo passou a ser MEB.

No entanto, da sua criação até 1962, o MEB - como sistema nacional - atuou numa linha desenvolvimentista, pregando o crescimento da economia nacional como saída para a crise econômica (crônica) da sociedade brasileira. Estava clara a ideia de que melhorando a economia, naturalmente elevar-se-iam as condições de vida do trabalhador, antevendo-se, assim, perspectivas para sua autopromoção.

Dada essa conotação pedagógica às suas ações, a Igreja preservou, assim, a hegemonia nessa comunidade de fiéis da área rural, neutralizando a influência comunista, mediante uma proposta de evangelização, onde estava implícita a elevação do nível de vida das populações rurais, embora em harmonia com a ordem capitalista vigente. Não é um acaso a proposta do cooperativismo, bastante difundida nos movimentos da Igreja de Natal.

A convocação do laicato para a evangelização/catequese foi resultado de uma política mais global da Igreja. A Diocese de Natal refletia as diretrizes da Igreja brasileira, que, desde 1921, com o Cardeal Leme, promovia a organização e unificação de movimentos leigos no país. Por sua vez, a Igreja brasileira refletia as diretrizes do Vaticano, que, em 1922, com Pio XI, criara oficialmente a Ação Católica, uma organização mais vigorosa e confiável, através da qual os leigos foram conclamados a participar "do apostolado hierárquico da Igreja", renovar a sociedade e estabelecer o reino universal de Cristo, negando "qualquer filiação partidária".

Até então, a participação dos leigos limitava-se à realização de tarefas secundárias, agora, passavam a atuar em áreas prioritárias para a Igreja, apresentando a vantagem de serem 
diretamente controlados pela hierarquia eclesiástica e, portanto, pretensamente isentos das pressões de uma organização de massas tradicional, como o partido ou sindicato.

Nessa perspectiva, cabe então perguntar: qual a proposta de sociedade que a Igreja apresenta? O Papa João XXIII, na Mater et Magistra, citando palavras de seu predecessor Pio XII indica oportunamente essa diretriz:

\begin{abstract}
A pequena e média propriedade agrícola artesanal e profissional, comercial e industrial, deve ser assegurada e promovida; as uniões cooperativistas devem garantir-lhes as vantagens próprias da grande exploração; e nas grandes explorações deve ficar aberta a possibilidade de suavizar o contrato de trabalho pelo contrato da sociedade (Igreja Católica, Papa, 1984, p. 29).
\end{abstract}

Eis, segundo os papas Pio XII e João XXIII, as estruturas econômicas que melhor se adequam à dignidade humana e melhor desenvolvem o sentido de responsabilidade. Delineia-se, nessa proposta, a versão do capitalismo atenuado ou terceira via, aceito e divulgado pela Igreja Católica como opção para o desenvolvimento econômico das populações.

\title{
4 REFERÊNCIAS BIBLIOGRÁFICAS
}

1. BARROS, Raimundo Caramuru. Brasil: uma Igreja em renovação. Petrópolis, Vozes, 1968.

2. CARVALHO, Marta Maria Chagas de. Uso do impresso nas estratégias católicas de conformação do campo doutrinário da pedagogia (1931-1935). Belo Horizonte, Cadernos ANPED, v. 7, p. 41-60, dez/1994.

3. CERTEAU, Michel de. A escrita da história. Rio de Janeiro: Forense Universitária, 1982.

4. CRUZ, Dalcy. A redenção necessária: Igreja Católica e sindicalismo rural. Campina Grande, 1982 (Dissertação de Mestrado em Sociologia). Centro de Humanidades. Universidade Federal da Paraíba.

5. ENCONTRO DOS BISPOS DO NORDESTE, 2. Natal (RN), 1959 [Resultados do Encontro]. Rio de Janeiro: Presidência da República. Serviço de Documentação, 1959.

6. FÁVERO, Osmar. Uma pedagogia da participação popular: análise da prática pedagógica do MEB - Movimento de Educação de Base: 1961-1966. São Paulo: 1984 (Tese de Doutorado). Pontifícia Universidade Católica de São Paulo.

7. FERRARI, Alceu. Igreja e desenvolvimento: o Movimento de Natal. Natal:Fundação José Augusto, 1968.

8. GÊ, Maria Zilda de Siqueira. As escolas radiofônicas no projeto de comunicação social da Igreja Católica. Natal: 1991. Dissertação (Mestrado em Educação). Centro de Ciências Sociais Aplicadas. Universidade Federal do Rio grande do Norte.

9. IGREJA CATÓLICA. Serviço de Assistência Rural. Relatório, 1959.

10. _ Açãa Católica Brasileira. Relatório - 1949. Natal, Centro de Imprensa S/A, 1950.

11. _. Papa. (1958-1963 João XXIII). Carta Encíclica Mater et Magistra. São Paulo:Edições Paulinas, 1984.

12. SPEYER, Anne Marie. A experiência da radiodifusão educativa. Natal, MEB, 1986. 
13. SAR. Sucinto Relato das atividades desenvolvidas pelo Serviço de Assistência Rural, no ano de 1956. Natal, 1957, mimeo.

14. RELATÓRIO DAS ATIVIDADES DESENVOLVIDAS PELO SERVIÇO DE ASSISTÊNCIA RURAL - S.A.R. NO RIO GRANDE DO NORTE. Natal, 1954, mimeo.

15. VIER, Frei Boaventura Kloppenburg. (Org.). Compêndio do Vaticano II: constituições, decretos, declarações. Petrópolis/RJ: Editora Vozes, 1991.

\section{NOTAS}

\footnotetext{
' Apud AMMANN, S. B. Ideologia do Desenvolvimento de Comunidade no Brasil. 7. ed. São Paulo: Cortez Editora, 1991, p. 32. In: CBCISS. Desenvolvimento de Comunidade Urbanas e Rurais. Rio de Janeiro, 1962, p. 25.

ii A Ação Católica foi criada por iniciativa do Papa Pio XI com o objetivo de promover a participação dos leigos nas atividades sociais da Igreja, tendo em vista a escassez do clero. No Brasil, sua criação ocorreu em 1935 pelo Cardeal Leme.

iii D. Eugênio Sales, já falecido, foi depois nomeado cardeal-arcebispo emérito do Rio de Janeiro.

iv Plano norte-americano de assistência técnica para a América Latina conhecido como Ponto IV, no contexto da Guerra Fria.
} 